\title{
EFICÁCIA DA CONFECÇÃO DE VÁLVULAS COLÔNICAS APÓS RESSECÇÃO RETOANAL EM RATOS
}

\author{
EFFICACY OF COLONIC VALVES CONFECTION AFTER ANORECTAL \\ RESECTION IN RATS
}

\author{
Sérgio Geraldo Veloso ${ }^{1}$ \\ Reginaldo Biet ${ }^{2}$ \\ Adriana Martins Rios ${ }^{3}$ \\ Virginia Hora Rios Leite ${ }^{4}$ \\ Alcino Lázaro da Silva, TCBC-MG ${ }^{5}$
}

\begin{abstract}
RESUMO: Objetivo: Testar a eficácia da construção de válvulas colônicas após a ressecção retoanal em ratos, para se obter retardo do fluxo intestinal. Método: Análise clínico-evolutiva, radiológica e anatomopatológica de 31 ratos submetidos a duas seromiotomias circunferenciais transversais no cólon com invaginação sero-serosa e ressecção retoanal, com colostomia perineal. Resultados: Sete ratos morreram no pós-operatório e, necropsiados, apresentavam impactação fecal. Houve redução do peso corporal e fecal no pós-operatório imediato (estatisticamente não significante), seguida de aparente normalização dos valores. Fecalitos aderidos uns aos outros foram freqüentes. Dos 24 animais radiografados, em oito, ao menos uma das válvulas estava visível. Após a necropsia de 21 ratos, constatou-se o predomínio absoluto de fezes a montante das válvulas. Macroscopicamente, nem sempre as válvulas foram identificadas. Na microscopia, encontrou-se hipertrofia das fibras musculares e interrupção da camada muscular com alteração na disposição das fibras e fibrose nos locais da seromiotomia. Conclusões: A operação foi tecnicamente viável. A presença das fezes a montante das válvulas, a eliminação de fezes aderidas, a hipertrofia e a interrupção da camada muscular reforçam a hipótese de que a seromiotomia age como mecanismo frenador, retardando o trânsito intestinal. O modelo experimental não permite aferir sobre continência fecal.
\end{abstract}

Descritores: Ressecção retoanal; Válvulas colônicas; Colostomia perineal; Cirurgia experimental.

\section{INTRODUÇÃO}

A amputação do conjunto esfincteral e a colostomia definitiva levam à incontinência fecal e ao conseqüiente uso de bolsa coletora abdominal ${ }^{1,2}$. As colostomias apresentam desvantagens, como prolapso, invaginação, isquemia, necrose, edema, estenose, colite, úlcera, intolerância à bolsa, odor, soltura da mesma, dentre outras ${ }^{1,3}$. Além disso, associam-se outras desvantagens como marginalização social, familiar e conjugal, dificuldades sexuais, eliminação de gases e ausência de controle do esvaziamento do cólon ${ }^{1,2}$.
Para se reduzir as inconveniências da incontinência fecal, tenta-se a colostomia no períneo com uso de artifícios para se obter alguma continência ${ }^{1,2,4}{ }^{6}$.

Com o advento das experiências de formação de válvulas no tubo digestivo, houve estímulo para associá-las à amputação do conjunto esfincteral e à colostomia perineal ${ }^{1,7-9}$. Esta técnica, no nível clínico ${ }^{8}$ e experimental ${ }^{9}$, demonstra resultados favoráveis. Há, no entanto, aspectos que ainda precisam ser verificados e explicados experimentalmente.

1. Médico Residente de Cirurgia Geral do Hospital das Clínicas da UFMG

2. Médico formado pela Faculdade de Medicina da UFMG

3. Médica Residente de Radiologia do Hospital das Clínicas da UFMG

4. Professor Adjunto do Departamento de Patologia da Faculdade de Medicina da UFMG

5. Professor Titular do Departamento de Cirurgia da Faculdade de Medicina da UFMG

Recebido em 06/11/2000

Aceito para publicação em 08/05/2001

Trabalho realizado no Departamento de Cirurgia da Faculdade de Medicina da Universidade Federal de Minas Gerais. 
Nesta pesquisa se testou, em ratos, a eficácia da técnica de ressecção retoanal com colostomia no períneo, associada à construção de válvulas colônicas, para se obter retardo do fluxo intestinal, através de análise clínico-evolutiva, radiológica e anatomopatológica dos animais operados.

\section{MÉTODO}

Após padronização da técnica cirúrgica, foram utilizados 31 ratos brancos machos da raça Holtzman, com idade entre 5 e 15 meses e peso de $209 \mathrm{~g}$ a $470 \mathrm{~g}$, alimentados com água e ração ad libitum, pesados e mantidos em gaiolas metabólicas individuais por três dias antes da operação. Nesse período as fezes foram colhidas e pesadas a cada dia. No pré-operatório imediato, os animais foram pesados.

Os animais foram anestesiados por inalação com éter sulfúrico e operados segundo a seguinte técnica:

- laparotomia mediana de aproximadamente $3 \mathrm{~cm}$

- construção de duas válvulas colônicas, a primeira a $7 \mathrm{~cm}$ da margem anal e a segunda $1 \mathrm{~cm}$ abaixo da primeira

- seromiotomia circunferencial (extramucosa)

- sutura invaginante da mucosa e submucosa através de 4 a 5 pontos sero-musculares com fio inabsorvível (polipropileno) para inversão de cerca de $0,3 \mathrm{~cm}$ (Figura 1).

- fechamento da laparotomia com fio absorvível
- dissecção retoanal com tração do cólon via perineal

- secção do cólon cerca de $1 \mathrm{~cm}$ acima do ânus

- exérese do conjunto retoanal

- colostomia perineal com fixação do cólon na pele, posteriormente ao escroto, no local antes correspondente ao ânus, com fio absorvível em pontos separados.

Nenhum preparo pré-operatório do cólon foi realizado; os animais mantiveram sua dieta até momentos antes da operação.

Após a operação, os animais continuaram em gaiolas individuais, sendo pesados no terceiro, sétimo e nono ou décimo dias. Suas fezes foram colhidas e pesadas diariamente, até o décimo dia pós-operatório, quando os ratos foram transferidos para gaiolas coletivas.

Diante de óbitos pós-operatórios, os animais foram necropsiados e avaliados macroscopicamente.

No período que variou de três semanas a quatro meses após a operação, 24 animais foram submetidos a enema opaco com contraste de bário diluído em água. Para tal foram anestesiados, com éter sulfúrico e após a imobilização, a solução com bário foi introduzida no cólon através de uma cânula e seringa, em quantidade variável, suficiente para produzir seu retrocesso e vazamento pelo ânus. Os animais foram radiografados 5 e 15 minutos após a introdução do contraste e as radiografias foram analisadas quanto ao número de válvulas visíveis.
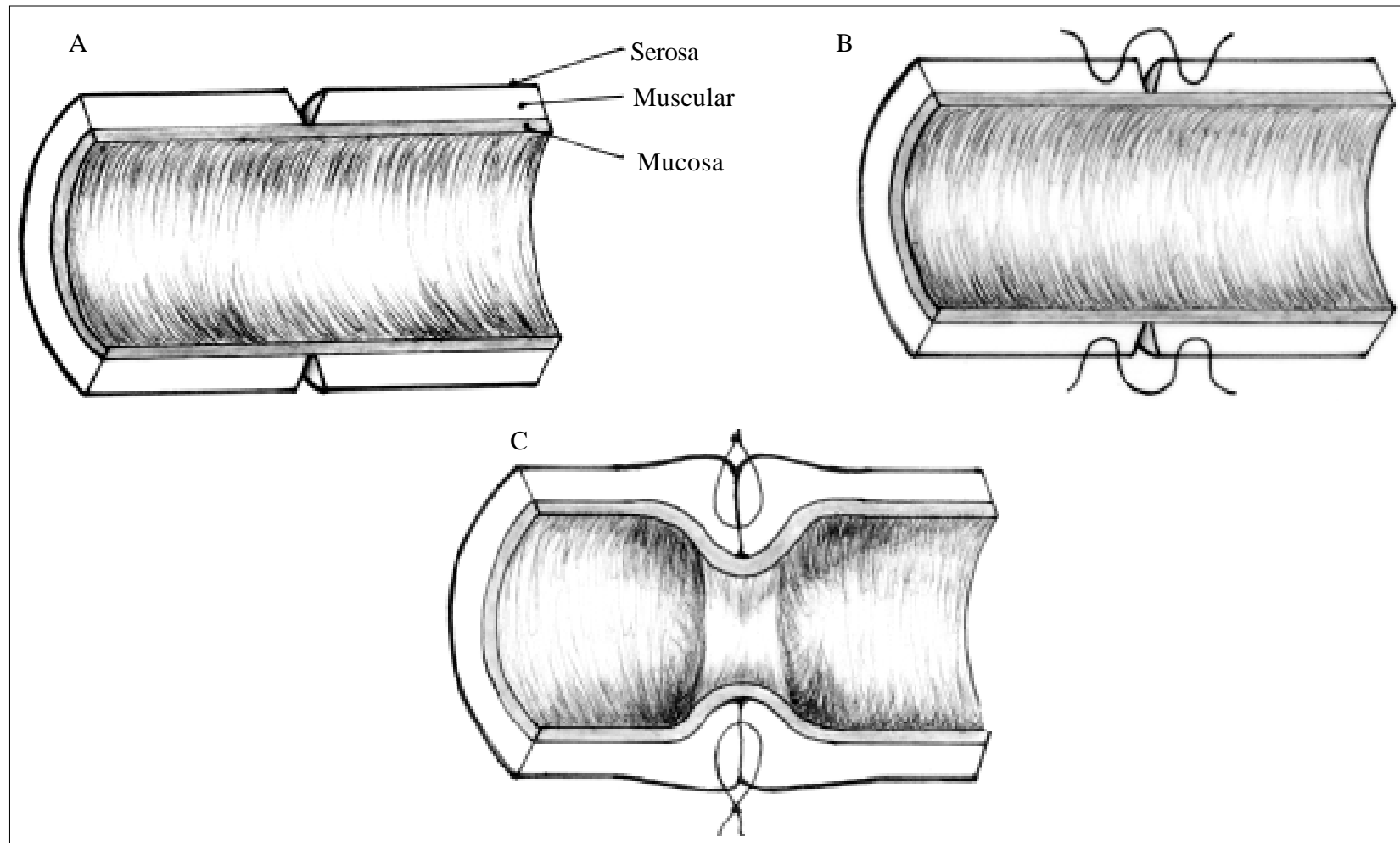

Figura 1 - Esquema ilustrando a confecção de válvulas colônicas, com realização de seromiotomia circunferencial extramucosa, seguida de pontos invaginantes. 
Um mês após a realização dos enemas opacos, os ratos foram mortos com éter e necropsiados, sendo feito o inventário da cavidade abdominal e a identificação externa das válvulas. O cólon foi fixado em formol a 10\%, após a retirada das fezes, e dele retirados seis fragmentos: o $1^{\mathrm{o}}$ perpendicular ao cólon, $1 \mathrm{~cm}$ acima da primeira válvula; o 2o longitudinal, seccionando a primeira válvula; o 30 perpendicular, entre as duas válvulas; o 4o longitudinal à segunda válvula; o 5ํ perpendicular, $1 \mathrm{~cm}$ abaixo da segunda válvula e o 6 o longitudinal, na área da colostomia. As válvulas foram analisadas macroscopicamente. $\mathrm{O}$ material foi então processado e corado em hematoclínico-eogino HE e tricrômio de Gomori, para análise à microscopia óptica.

Dois ratos adicionais, controles, foram operados de modo semelhante (laparotomia, ressecção retoanal e colostomia perineal) sem realização das válvulas, sendo também pesados e tendo suas fezes colhidas nos mesmos dias que os demais. Foram submetidos ao enema opaco e necropsiados para estudo anatomopatológico. Dois outros animais sadios, não operados e mortos com outra finalidade, foram utilizados como controle de normalidade para a anatomia patológica.

\section{RESULTADOS}

A idade dos animais variou de cinco a 15 meses, com média de 9,5 $\pm 3,3$ meses e o peso, de $209 \mathrm{~g}$ e $470 \mathrm{~g}$, com média de $364 \pm 59 \mathrm{~g}$, sendo operados em momentos diferentes num intervalo de seis meses.
O tempo cirúrgico médio foi de $77 \pm 12$ minutos, sendo maior nos primeiros animais operados que nos últimos.

Durante a seromiotomia ocorreram perfurações acidentais punctiformes na mucosa, de até $2 \mathrm{~mm}$, expondo a luz intestinal. Estes locais eram invaginados juntamente com a mucosa e submucosa ao se realizar o anodamento dos fios.

Dos 31 animais operados, sete evoluíram para óbito no período de três a 16 dias pós-operatórios. À necropsia, apresentavam distensão abdominal e impactação fecal a montante das válvulas.

Na Tabela 1, vê-se o peso dos animais. Houve tendência à redução do peso no 3 o e 7o dias pós-operatórios e recuperação parcial no 9o ou 10ํㅡㄹ dia, apesar de estatisticamente não haver diferença significante.

$\mathrm{Na}$ Tabela 2, observa-se variação do peso fecal nos períodos pré e pós-operatório. Houve queda deste, verificada nos três primeiros dias pós-operatórios e tendência à normalização nos dias seguintes. A diferença não foi estatisticamente significante.

Ao se comparar o peso fecal médio entre os ratos vivos e os mortos (Tabela 3), constata-se que é bem menor entre aqueles que morreram, o que é estatisticamente significante.

No pós-operatório, inicialmente as fezes eram diarréicas. Posteriormente, apresentaram eliminação de fecalitos semelhantes aos do pré-operatório, entre os quais havia fecalitos impactados (aderidos entre si). Gradualmente retornaram ao aspecto normal, mas fecalitos impactados con-

Tabela 1

Peso dos ratos nos períodos pré e pós-operatórios

\begin{tabular}{|c|c|c|c|c|}
\hline Período & Peso $(g)$ & №. de Ratos & Valor de Kruskal Wallis ${ }^{1}$ & Valor $p^{l}$ \\
\hline Pré-operatório & $362 \pm 57$ & 31 & - & - \\
\hline 3ํ dia pós-operatório & $333 \pm 55$ & 29 & 27,95 & 0,310 \\
\hline 7ํ dia pós-operatório & $332 \pm 62$ & 16 & 15,00 & 0,451 \\
\hline $9^{\circ}$ ou $10^{\circ}$ dia pós-operatório & $344 \pm 43$ & 27 & 25,92 & 0,411 \\
\hline
\end{tabular}

Fonte: dados coletados

Notas: 1) Valor de Kruskal Wallis e valor p foram obtidos comparando-se o peso do dia referido com o peso pré-operatório.

Tabela 2

Peso fecal médio nos períodos pré- e pós-operatórios

\begin{tabular}{|c|c|c|c|c|}
\hline Período & Peso das Fezes ${ }^{l}$ & № de Ratos & Valor de Kruskal Wallis ${ }^{2}$ & Valor $p^{2}$ \\
\hline 3 dias pré-operatório & $10,70 \pm 2,17$ & 31 & - & - \\
\hline 1ำ2e e 3ํ dias pós-operatórios & $4,42 \pm 3,64$ & 31 & 22,65 & 0,362 \\
\hline 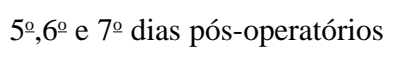 & $11,23 \pm 5,62$ & 25 & 21,63 & 0,542 \\
\hline 8우ํํ10o dias pós-operatórios & $9,43 \pm 4,18$ & 22 & 18,14 & 0,577 \\
\hline
\end{tabular}

Fonte: dados coletados

Notas: 1) Peso médio das fezes no período referido em g/dia

2) Valor de Kruskal Wallis e valor p foram obtidos comparando-se o peso fecal médio do intervalo referido com o peso fecal médio nos três dias pré-operatórios. 
Tabela 3

Peso fecal médio dos ratos vivos e mortos nos três primeiros dias pós-operatórios ${ }^{1}$

\begin{tabular}{l|c}
\hline Ratos & Peso fecal $^{2}$ \\
\hline Vivos (24) & $4,96 \pm 3,22$ \\
Mortos (7) & $2,55 \pm 4,63$ \\
\hline
\end{tabular}

Fonte: dados coletados

Notas: 1) Kruskal Wallis $=5,70$ valor $p=0,016$;

2) Peso médio das fezes em g/dia

tinuaram a ocorrer. Os ratos-controle operados também apresentaram fezes diarréicas no início, com posterior retorno ao formato e consistência usuais dos fecalitos.

O estudo radiológico foi realizado no período de três semanas a quatro meses do pós-operatório, sendo possível a identificação de algumas válvulas. $\mathrm{O}$ contraste baritado permitiu a identificação de falhas de enchimento ao longo do cólon, compatíveis com a presença de fezes. Usualmente não havia fezes a jusante das válvulas, fato comprovado pela facilidade com que se introduzia e se retirava a cânula e pelo exame radiológico. Foram radiografados 24 ratos. Destes, em 16 animais nenhuma das válvulas foi identificada. Em cinco outros, apenas uma válvula foi identificada e em três ratos as duas válvulas estavam bem nítidas (Figura 2). Dividindo-se estes 24 animais em quatro grupos segundo o tempo pós-operatório, indo do maior tempo para o menor, formou-se quatro grupos com seis animais. Em cada grupo havia dois animais com válvulas identificáveis. Nos dois ratos operados, mas sem a confecção das válvulas, o exame radiológico não evidenciou saliências ou depressões na luz intestinal.

A necropsia de 21 animais evidenciou aderências conjuntivas de intensidade variada, envolvendo omento, vesículas seminais, intestino delgado, ceco, cólon e especialmente as válvulas. Dezenove dos 21 animais apresentaram impactação fecal a montante das válvulas (Figs. 3 e 4). Em apenas três dos 21 animais foram vistas fezes a jusante das válvulas, mesmo assim em dois deles as fezes predominavam a montante. Em apenas um ocorreu inversão com predomínio absoluto de fezes a jusante. Em um animal todo o cólon encontrava-se sem fezes. Os dois animais-controle colostomizados, sem válvulas, apresentaram todo o cólon sem fezes (Figuras 3 e 4A).

À abertura do intestino, as válvulas nem sempre foram macroscopicamente identificadas; apesar de o local de construção das mesmas ser evidenciado pela presença dos pontos cirúrgicos (Figura 4B).

Observou-se hipertrofia das camadas musculares do intestino grosso, evidenciada pelo espessamento da camada muscular e aumento das dimensões das células musculares (Figuras 5B e 5D), identificada em todo o segmento colônico estudado, das válvulas à colostomia no períneo.

No local da seromiotomia, à microscopia óptica, havia alteração na disposição das fibras musculares, que não se apresentavam paralelas umas as outras. A interrupção da camada muscular por interposição de fibrose era co-

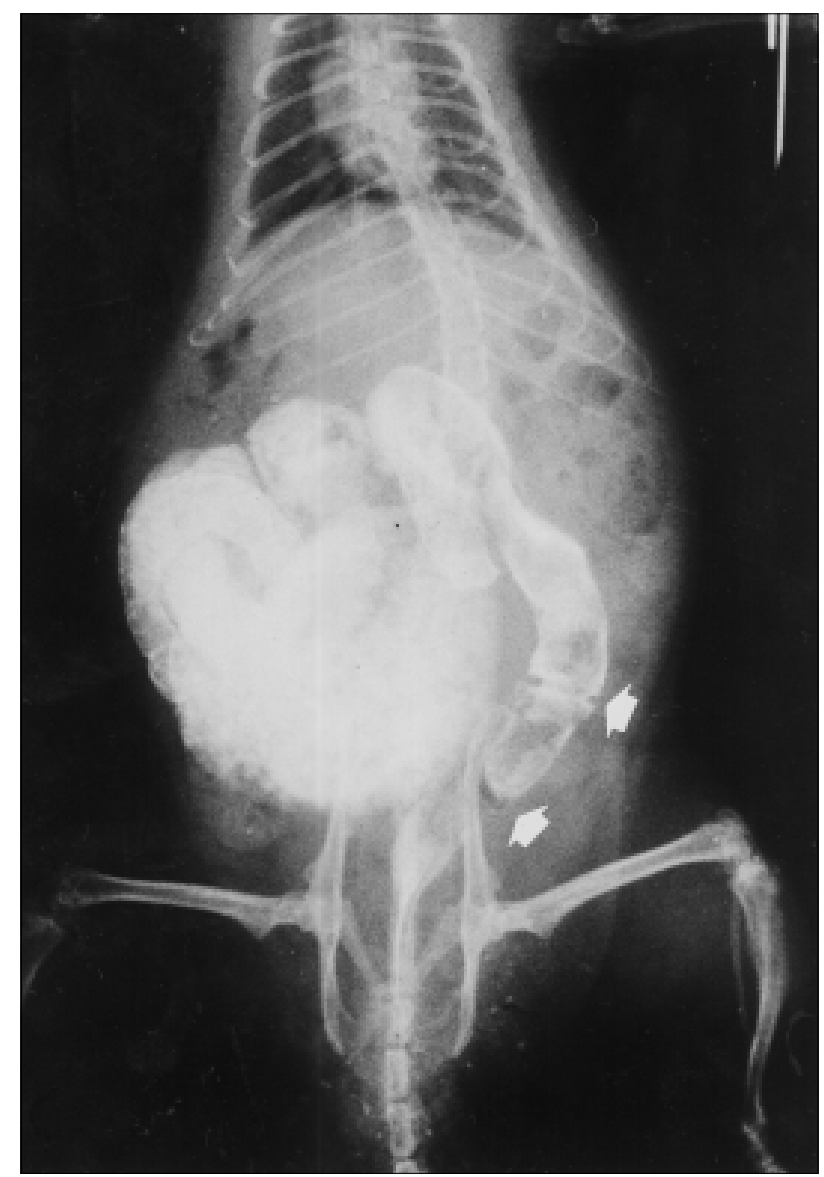

Figura 2 - Enema opaco evidenciando as duas válvulas colônicas (setas).

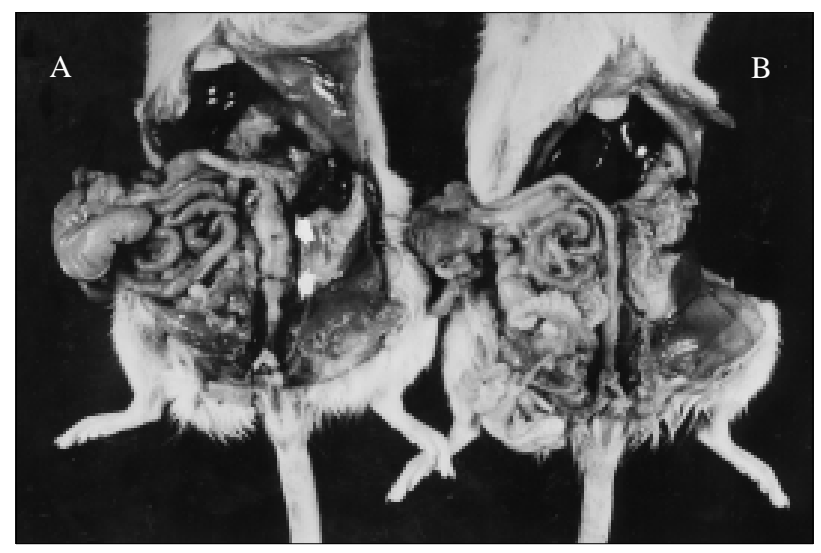

Figura 3 A e B - Ratos submetidos a colostomia perineal após amputação retoanal. $O$ da esquerda apresenta as duas válvulas colônicas (setas) e impactação fecal a montante. No rato da direita, não foram feitas válvulas, estando o cólon livre de fezes.

mum (Figuras 5C e 5D). Além destes, constatou-se deposição de fibrina na serosa (Figuras 5B e 5D), reação gigantocelular aos fios de sutura (Figura 5D), parasitos na luz intestinal, além de colônias bacterianas na parede intestinal. $\mathrm{Na}$ área 6, área da colostomia, comumente havia úlceras na 

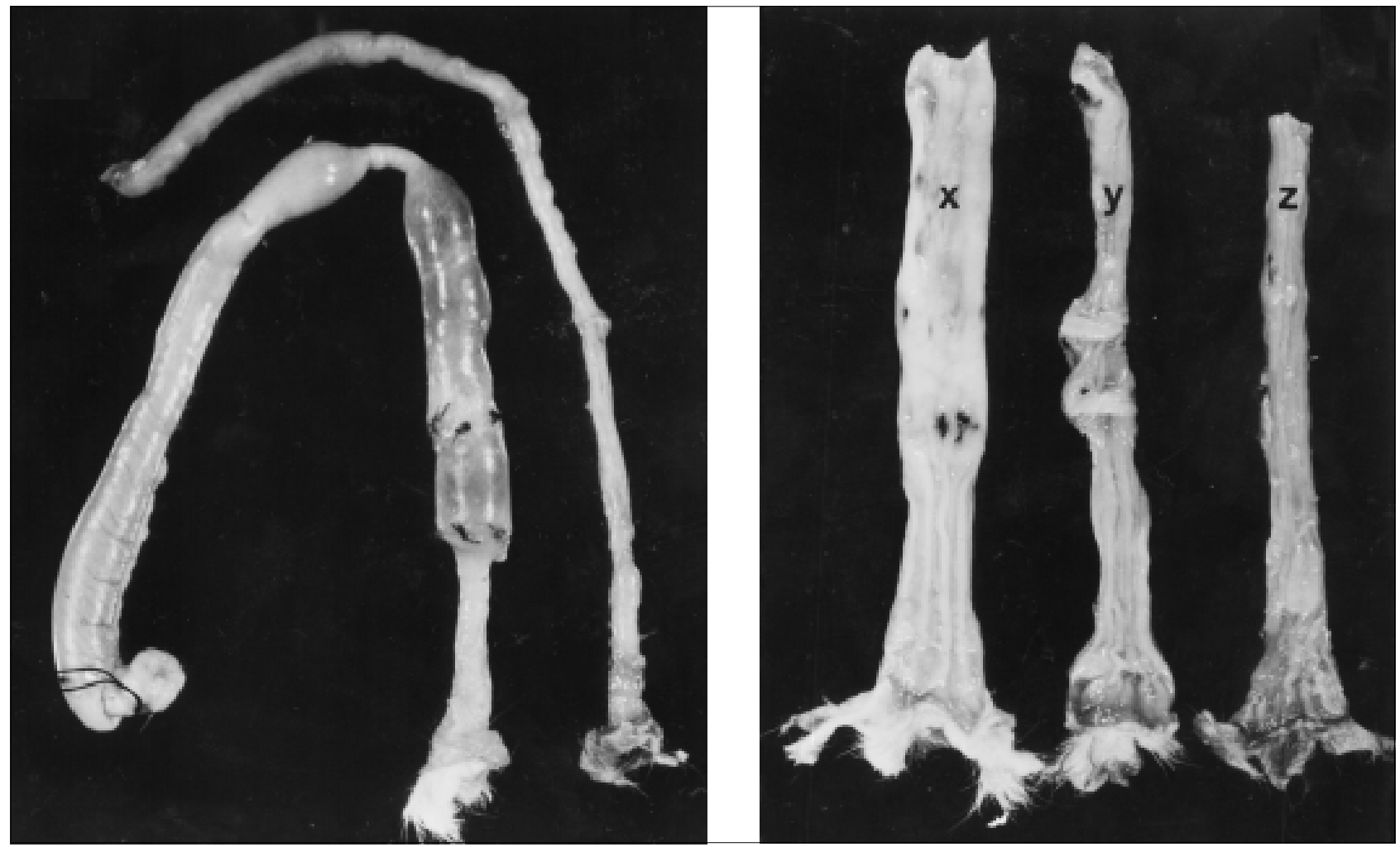

Figura 4 - Cólons de ratos após dissecção. Em A, à esquerda, identificam-se os pontos das válvulas e impactação fecal a montante. À direita, cólon sem válvulas e sem fezes. Em B, três cólons abertos longitudinalmente. Em x e y, foram construídas válvulas colônicas. Em x as válvulas não estão definidas macroscopicamente; em y, se mostram bem evidentes; e em z não se construíram as válvulas.

transição cutaneomucosa. Nestas regiões ocorreram muito freqüentemente metaplasia escamosa do epitélio intestinal.

Nos quatro animais controles (dois colostomizados e dois não colostomizados), não houve hipertrofia das camadas musculares do intestino (Figura 5A).

\section{DISCUSSÃO}

Os animais, apesar de adultos, apresentavam variação de idade e peso bem grandes, isto certamente prejudicou a criação de um grupo homogêneo; por outro lado permitiu que a técnica fosse feita em animais de tamanhos diferentes, com diferentes espessuras do cólon.

Não foi do interesse dos pesquisadores a criação de um grupo-controle, mas apenas ter um referencial de normalidade, para isso serviram os quatro animais.

A técnica operatória de construção das válvulas é relativamente simples de ser realizada ${ }^{8,9}$. O tempo mais laborioso é a realização da seromiotomia extramucosa, onde algumas vezes houve pequenos pontos de perfuração da mucosa, que foram invaginados juntos com a seromiotomia. Inicialmente estas perfurações acidentais foram descritas como intercorrências operatórias. Como isto aparentemente não tinha valor prognóstico para os animais, estes eventos não foram valorizados. O número correto de animais em que o segmento foi perfurado não foi contado.
Os ratos que morreram no pós-operatório, o que ocorreu entre o 3o e o 160 dia, à necropsia, apresentavam impactação fecal no nível das válvulas 9 . O exame histológico não foi realizado, já que geralmente eles se encontravam em algum estado de decomposição ao se constatar o óbito. A morte destes animais pode ter advindo do próprio ato operatório, infecções ou contaminações, obstrução intestinal e formação de fecaloma, dentre outros fatores. Estenose ao se criar a válvula, gerando obstrução intestinal deve ter sido uma causa importante de morte. A distensão abdominal encontrada pode ser parte do quadro de obstrução intestinal ou dos fenômenos degenerativos. Possivelmente, diante de técnica asséptica adequada o número de óbitos seria menor.

As reduções dos pesos corporal e fecal no pós-operatório são condizentes. Em decorrência do estresse cirúrgico e conseqüente liberação de cortisol, espera-se que haja mobilização de energias armazenadas, catabolismo intenso, e perda de peso. Como toda intervenção intestinal, durante algum período espera-se a existência de íleo funcional, reduzindo o volume fecal e possivelmente o apetite dos animais. A redução persistente do peso fecal teve significado prognóstico, já que os animais que apresentaram progressão da redução evoluíram para o óbito.

A observação das fezes agrupadas na gaiola, associada a impactação fecal a montante das válvulas, condiz 
com possível ação frenadora das válvulas à eliminação das fezes ${ }^{1,9}$. Uma vez que o volume fecal volta à normalidade $\mathrm{e}$ os ratos recuperam-se em estado geral, espera-se que a fisiologia intestinal do rato esteja em homeostase. A presença das fezes a montante das válvulas, impactadas, e não espalhadas pelo intestino como acontece num rato
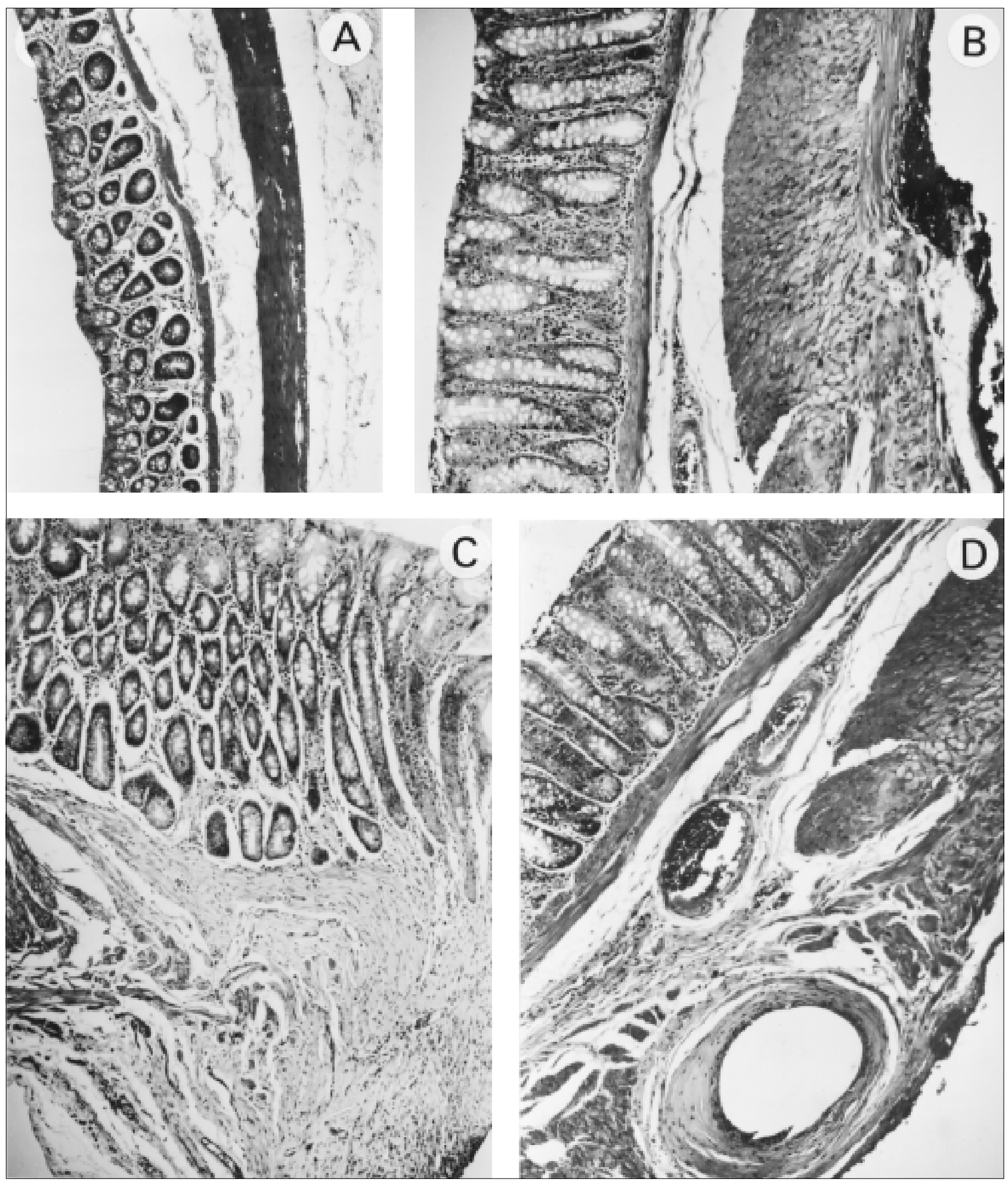

Figura 5 - Histologia da parede colônica de ratos (aumento de 63x). Em A, controle. Em B, C e D, ratos operados; nestes a camada muscular esta espessada por hipertrofia (B e D). Na região da seromiotomia há interrupção da camada muscular com fibrose $(C$ e $D)$. Área cística com reação giganto-celular ao fio de sutura (D). Deposição de fibrina na serosa em $B$ e $D$. 
normal, permite supor que haja atraso no fluxo intestinal naquele ponto. Este atraso certamente está longe de ser uma continência fecal, mas pode ter funcionado como redutor do número de evacuações, esperadas com a ausência do esfíncter. No rato, onde o número de evacuações por dia é difícil de ser quantificado, a comprovação da redução das evacuações fica inviável através deste modelo experimental. $\mathrm{O}$ ideal seria um modelo experimental que permitisse quantificar o número de evacuações. Neste caso, um grupo-controle se tornaria útil.

À radiologia, nem sempre as válvulas foram identificadas, podendo ser resultante do enchimento excessivo do intestino com o bário e distensão do mesmo. Já que os animais não receberam nenhum preparo intestinal, a presença das fezes na luz intestinal provocou falhas de enchimento, que podem ter contribuído para a não identificação das válvulas. Outro motivo, poderia ser a própria ausência da válvula, constatada posteriormente, à necropsia. Infelizmente não foi possível comparar o aspecto radiológico aos achados da necropsia. Esta foi realizada por pesquisadores diferentes, sem uma devida uniformização dos achados macroscópicos das válvulas. A variação do tempo pós-operatório não teve influencia na identificação das válvulas nos animais, como o que se percebe com a divisão dos ratos nos quatro grupos, onde não houve predominância dos achados em um tempo específico.

À microscopia, a região de confecção das válvulas (seromiotomias) foi sempre identificada, havendo interrupção da camada muscular, desordem das fibras musculares e fibrose. Comum também era a hipertrofia muscular nos segmentos estudados, encontrada do segmento colônico acima das válvulas até a colostomia, sem predomínio de uma região sobre outra. Isto condiz com o possível mecanismo frenador criada pelas válvulas, exigindo contrações mais fortes para a propulsão das fezes.

Diante do achado de impactação fecal, interpretado como sendo redução do fluxo intestinal, da ausência das válvulas em algumas peças, bem como da presença de secção muscular com fibrose nos locais da seromiotomia, julga-se que a seromiotomia seria responsável por uma altera- ção do peristaltismo local. Isto poderia explicar a presença de hipertrofia muscular, resultante de contrações mais fortes para superar os obstáculos do cólon. A secção da camada muscular seria acompanhada de secção dos feixes do plexo de Auerbarch, prejudicando a propagação do impulso motor. A fibrose teria papel importante, impedindo, ou diminuindo, o restabelecimento dos feixes nervosos e, conseqüentemente, impedindo a transmissão das ondas. A invaginação das extremidades seccionadas teria o objetivo de aumentar a fibrose local. Uma vez que não há como precisar quão perfeita foi a seromiotomia extramucosa, certamente com a técnica, estaríamos reduzindo e não eliminando a conexão entre os dois segmentos intestinais envolvidos na construção da válvula. A presença da válvula, ou melhor, da invaginação, nos casos em que ela esteve presente, também pode contribuir para a redução do fluxo intestinal, já que a mesma funcionaria como um obstáculo mecânico intraluminar a ser vencido pelos fecalitos impactados.

Cabem algumas críticas como a ausência de uniformização de critérios para se quantificar as válvulas durante a necropsia. A impossibilidade deste modelo experimental de dar informações mais precisas sobre continência fecal, aqui definida como capacidade de retenção das fezes, e sua eliminação voluntária.

O passo seguinte que poderá ser testado é o estudo manométrico ${ }^{9,10}$ para se verificar a pressão nos segmentos intestinais envolvidos, o que forneceria dados sobre o funcionamento valvular e o mecanismo propulsor criado.

A técnica de construção de válvulas intestinais não resulta em continência fecal para o paciente, o que parece acontecer é um retardo do fluxo intestinal ${ }^{1,8,9}$. Isto poderia ser benéfico ao homem pois permitiria menor número de eliminações ao dia, como encontradas em pacientes com colostomia sem artifícios frenadores ${ }^{1,2}$, com possibilidade de acomodação horária das mesmas, até mesmo com programação de suas dejeções ${ }^{1,8}$.

A operação demonstrou-se tecnicamente viável e os resultados encontrados na clínica e em nosso experimento parecem ser promissores ${ }^{1,8,9}$.

\begin{abstract}
Background: The present study intend to test the efficacy of colonic valves construction after the anorectal resection in rats, in order to obtain retardation of the intestinal flow. Method: Clinical, radiological and anatomopathological analysis, ranging from 31 rats, submited to a series of two colonic transversal-circunferential seromiotomies, followed by serous-serous invagination and anorectal resection, and a perineal colostomy. Results: Seven rats have died in the post-operatorium and, when necropsied, they presented faecal impactation. There was reduction in both body and faecal weight in the immediate post-operatorium period (statistically not significant), followed by an apparent normalization of the values. Small stool were found frequently joined together. In eight animals, from twenty-four which underwent radiograph, at least one valve was visible. After the necropsy of 21 rats, there was a major predominance of faeces above the valves. Macroscopically, the valves were not identified quite often. Microscopically, hipertroph in muscle fibers and interruption in muscle lay with alteration in fibers disposition and fibrosis in the places of seromiotomy, were commomly found. Conclusions: The operation can be considered as being tecnically viable. The presence of faeces above the valves, the elimination of joined stools, the hipertrophy and interruption of muscle layer, all emphasize the hypothesis that seromiotomy acts as a braking mechanism, retarding the intestinal flow. The experimental model adopted does not allow us to make any gauging regarding to faecal continence.
\end{abstract}

Key Words: anorectal resection, colonic valves, perineal colostomy, experimental surgery 


\section{REFERÊNCIAS}

1. Lázaro da Silva A - Tratamento do Câncer Reto-anal. Colostomia Perineal. São Paulo - Atheneu, 1998.

2. Ma S, Leu SY, Fang RH - Reconstruction of anorectal angle after abdominoperineal resection of rectum and anus: an animal model. Ann Plast Surg, 1989; 23(6):519-522.

3. Imbembo AL, Lefor AT - "Carcinoma do cólon, do reto e do ânus". In Sabiston DC (ed) - Tratado de Cirurgia As bases biológicas da prática cirúrgica moderna. 14 Edição. Rio de Janeiro. Guanabara Koogan, Volume 1, 1991; pp. 892-905.

4. Gamagami RA, Chiotasso P, Lazorthes F - Continent perineal colostomy after abdominoperineal resection: outocome after 63 cases. Dis Colon Rectum 1999; 42(5):626-630.

5. Altomare DF, Rinaldi M, Pannarale OC at al. - Electrostimulated gracilis neosphincter for faecal incontinence and in total anorectal reconstruction: still an experimental procedure? Int J Colorectal Dis, 1997; 12(5):308-312.

6. Santoro E, Santoro R, Santoro E - Perineal reconstruction with continent colostomy after the Miles operation. Semin Surg Oncol, 1994; 10(3):208-216.

7. Lázaro da Silva A - Abdominoperineal excision of the rectum and anal canal with perineal colostomy. Eur J Surg, 1995; 161:761-764.

8. Vielitchkov NG, Kirov GK, Losanoff JE, at al. - Abdominal resection and perineal colostomy for low rectal cancer - The Lazaro da Silva technique. Dis Colon Rectum, 1997; 40(5):530-53.
9. Silva Júnior AL. Histopatologia da seromiotomia dupla e sutura seromuscular no cólon descendente de ratos. Dissertação (Mestrado em Técnica Cirúrgica e Cirurgia Experimental). Belo Horizonte. Universidade Federal de Minas Gerais, 2000; 65 p.

10. Lestar B, Penninckx F, Bouckaert W, at al. Valvular colonic sphincter substitutes. Na experimental study in dogs. Eur Surg Res, 1993; 25(2):123-128.

Endereço do autor para correspondência Prof. Alcino Lázaro da Silva, TCBC

R Guaratinga, 151

30315-430 - Belo Horizonte-MG 